\title{
The role and progress of EIA in environmental protection in China
}

\author{
Yingying $\mathrm{Wu}^{1}$ \\ ${ }^{1}$ Qingdao jialan environmental protection technology co., ltd, Qingdao, 266000, China
}

\begin{abstract}
The Environmental Impact Assessment system, referred to as the EIA system, is to evaluate the impact of the implementation of the plan or the construction and operation of the project on the environment, combine the surrounding environmental quality status, propose ecological or environmental protection measures, then evaluate the effectiveness of the measures, and draw a conclusion on the feasibility of the project(planning) in terms of environmental protection. This article summarizes the role and progress in environmental protection in the two aspects of planning and construction projects in recent years.Comprehensively selected cases found that both planning or construction project environmental assessment have played an important role in predicting the possible impact of planning or construction projects on the environment and ecology, and proposed feasible and effective environmental protection measures.After the planning or construction project adopts the conclusions and suggestions, as long as the "Three Simultaneous" regulations are followed, the impact of the planning or construction project on the environment or ecology can be prevented or effectively reduced. When it is necessary to conduct postevaluation of environmental impact, verify the actual conditions of the construction project, such as emissions and actual production processes.
\end{abstract}

\section{Overview}

In the process of rapid economic and social development in China, people need to evaluate the ecological and environmental impacts of planning implementation or construction project construction, and make a decision on whether the planning or project is feasible. An Environmental Impact Assessment (EIA) system began to gradually develop, and established in China and other major countries in the world.

After the establishment of the EIA system, the relevant guidelines and standards of the EIA work are also coordinated with the environmental quality standards, and gradually developed and improved, combined with the continuous development of environmental protection technology, and the ability to make decisions for the feasibility of the project in terms of environmental impacts is gradually improving. The EIA can be divided into planning and construction project EIA according to the classification of the evaluation objects, or can be classified into environmental quality and prediction assessment, and environmental impact post-assessment based on assessment time.

\section{The impact of EIA on planning implementation}

\subsection{The significance of planning EIA}

${ }^{a}$ Corresponding author:wuyingying198807@163.com
The "Regulations on Environmental Impact of Planning" stipulates that the EIA of planning is to analyze the impact of the implementation of the plan on the relevant regions, river basins and sea areas, predict the impact of the environment, care about the health of the population under the implementation of the plan, promote comprehensive coordination between economic, social and environmental benefits after the implementation of the plan.The planning environmental assessment is to improve the scientific nature of the planning from the environmental point of view, and reduce environmental pollution and ecological damage from the source.

\subsection{Basic method of planning EIA}

The "Regulations on EIA for Planning" and related documents stipulate that the "Three Lines and One List" evaluation method is the basic method of planning EIA, and can also successfully guide planning to complete the tasks of environmental and ecological protection.

"Three Lines and One List" refers to "the red line of ecological protection, the bottom line of environmental quality, the upper limit of resource utilization, and the list of environmental access."The pollution sources in the plan should not allow the concentration of environmental pollutants to exceed the environmental quality standard, that is, the "bottom line" of environmental quality; The plan should also pay attention to the utilization of energy, water, land and other resources in various regions, and cannot exceed the 
"upper limit" of the relevant region; There must also be a planned negative list of environmental access, that is, construction projects that discharge of certain pollutants, or whose concentration or total amount of pollutants are significantly larger, are not allowed in the plan. Chen Paichao[1] analyzed the "Three Lines and One List" of planning in the process of preparing the planning EIA report of the starting area of a high-tech industrial base, and believed that the scientific formulation of the "Three Lines and One List" of the evaluated planning area is the focus of planning EIA. Shao Wei[2] illustrated this point by taking the Jiulong River water system (in Zhangzhou) under $0.5 \mathrm{~km} \sim 2 \mathrm{~km}$ of the comprehensive planning ring evaluation example.

\subsection{The role of planning EIA in planning}

The planning environmental assessment can make the planning achieves the optimization of the combination of economic benefits and environmental protection.

Compared with the provisions of the "Regulations on EIA for Planning", the " Three Lines and One List " evaluation method can successfully guide planning to complete the tasks of environmental and ecological protection. Wang Yonghong and others[3] reviewed the EIA work of a certain province's coal power base planning and affirmed the effect of the work results on the optimization of the plan's scale, layout, structure, construction timing and other planning implementation content, that is, comprehensive evaluation is carried out from the aspects of coal economy, technology, pollutant control, etc., so that the plan is implemented with the best plan. Li Hui and others[4] conducted research on the construction of the power grid planning EIA system, and carried out practical application in Jingzhou, Hubei, realized the adjustment of the planning EIA to the planning plan, and reduced the noise and electromagnetic field impact in the surrounding environmentally sensitive areas during the planning stage, promoted the adjustment of other related plans that are restricted by the plan, and provides support for optimizing the power grid planning EIA system. Zhang Yuhuan and others[5] pointed out that the EIA of the comprehensive planning of the river basin is not specific enough to implement the "three lines and one single", the optimization plan is conservative, and the mitigation measures are not strong, the method of environmental protection objectives is clarified, and the framework of the river basin EIA indicator system is proposed, which provides a reference for planning EIA work in different basins. Rong Weiying and others [6] conducted research on the application of pollution permits and "Three Lines and One List" in planning EIAs, and believed that pollutant discharge permits can be connected with the "Three Lines and One List", combined with the environmental status and predicted results investigated in the planning EIA, can become the basis for relevant data in the pollutant discharge permits, and the use of pollution monitoring guidelines can optimize the followup evaluation of planning environmental impacts. Liang Rui and others[7] believe that improper planning and layout of the modern coal chemical industry may cause environmental risks and other major problems, and others put forward suggestions for the environmental access and development of the modern coal chemical industry. They believe that the role of planning and environmental assessment should be played well, and the completed projects should be tracked and evaluated, and the construction of relevant standards should be promoted.

In a word, the planning EIA takes "Three Lines and One List" as the main method, which plays a guiding role in the environmental protection work during the implementation of the plan.

\section{The impact of EIA on the construction and operation of construction projects}

\subsection{The relationship between construction project and planning EIA}

Construction projects must be built in corresponding planning, and EIA of construction projects should be based on the conclusions of the planning EIA. Areas where the planning EIA work has not been completed shall not be newly constructed with environmental pollution projects. In today's relevant laws, regulations and policies, the linkage between the two is increasingly emphasized.To meet these requirements, construction projects must have effective environmental protection measures to reduce the emission of "three wastes". The environmental protection facilities of the construction project must be designed, constructed, and put into operation at the same time as the main body of the construction project ,that is, "Three Simultaneous".

The EIA of construction projects should also follow the analysis results of "three lines and one single", that is, the red line of ecological protection must not be crossed, the bottom line of environmental quality must be maintained, the upper limit of resource utilization restricts the level of resource consumption of construction projects, the access system is the threshold for construction projects to enter the planning area. Huang Wen[8] and others discussed the geological EIA and prevention measures of the Tanjiabian coal mine in Sichuan Province. They believed that the mining of coal mines aggravated the slope and other geological disasters, and aggravated the deformation of houses. After mining stopped, the disasters were gradually weakened, it exactly illustrates the correctness of the "resource utilization upper limit". Fan Fan[9] analyzed the pollution characteristics and evaluation factors of the cement industry, industrial policies and air pollution emission standards, analyzes the pollutant emission during the construction period, operation period and service period of the project, finds the law of accidental discharge, puts forward environmental protection measures to increase the unorganized emission of particulate matter, puts forward requirements for strengthening control of abnormal emissions, and strictly adheres to the "bottom line" of air quality. Shi Zhenwu[10] and others innovatively proposed to use 
frozen soil environment as an important aspect of the evaluation of ecological environment in cold areas to improve the comprehensive evaluation index system of ecological environmental impact during road construction, and established a TOPSIS model to evaluate actual roads. The evaluation results show that the model is suitable for the ecological environment impact assessment of the highway construction area in Heilongjiang.

\subsection{The role of construction project EIA in environmental protection}

The EIA of a construction project consists of two parts. One part is the assessment of the impact of the surrounding environment on the project itself, and the other part is the impact of the construction project on the surrounding environment during or after completion. The purpose of the environmental assessment of construction projects is to avoid the project's own emissions from damaging the surrounding environment, but also to avoid the impact of other projects or external pollution sources on the project itself.

$\mathrm{Xu}$ Cong[11] and the other took the newly planned plot of Metro Line 1 in a certain city as an example to explore the impact of subway underground line vibration and secondary structural element noise on the distance of the planned plot, and optimized the distance of the surrounding planned plot. In this way, the construction project in the planning plot must consider the problem of subway vibration. The prediction content of vibration in the EIA can be used to estimate the distance of the construction project in the plot. This distance can not only make the vibration impact of the construction project negligible, but also not to compromise and waste valuable land. Chen Ye[12] sorted out the key contents and common problems of the EIA of hospital construction projects. For example, hospital wastewater contains a large number of pathogenic microorganisms and chemical pollutants such as drugs, disinfectants, and diagnostic reagents. Therefore, the treatment process of hospital wastewater is different from that of domestic sewage. The impact of the external environment on the hospital cannot be ignored, such as the surrounding road traffic noise and industrial enterprise pollution, so this puts forward special requirements for the hospital's noise reduction and site selection. Liu Biao[13] analyzed the main points of the EIA of domestic waste incineration power generation projects, believed that although the construction and operation of such projects can digest excessive domestic waste and use domestic waste as energy, it is necessary to avoid environmentally sensitive areas to prevent secondary pollution caused by pollutants discharged by the project.

\section{The role of EIA in environmental protection}

\subsection{Circumstances requiring post-evaluation of environmental impact}

If the project is in the process of construction or operation, there exist some situations that does not meet the approved EIA documents, for example, there are changes in the process of construction and changes in environmental protection facilities, the efficiency of environmental protection facilities cannot meet the original requirements, the surrounding environmental quality has undergone major changes, environmental protection goals, evaluation standards have been improved, and total control indicators have changed, the environmental impact post-assessment should be carried out. If the change reaches a certain level, it is necessary to resubmit the EIA document for approval. In addition, certain types of construction projects require post-EIA after the project starts operation, such as oil field projects and mine projects. Wang Wenting and others[14] summarized the characteristics of the post-evaluation of oilfield development and construction projects, and discussed the problems of soil and groundwater tracking and monitoring. Liu Shengjun[15] conducted a brief analysis of the post-evaluation documents of the Yanshan Iron Mine during a period of operation. The document evaluates the changes in regional environmental quality, examines the ecological and environmental evaluation of surface water and groundwater, and believes that post-evaluation is of great significance for the future environmental management of iron mines. Wei Chengbin[16] conducted a postassessment on the decommissioning project of a certain uranium mine site geological exploration facility from both the radiation environment and the ecological environment. He believed that both the radiation environment and quality environment of the project could be improved, and at the same time the ecological environment damage caused by the mine was restored.

\subsection{The role of environmental impact post- assessment}

\subsubsection{Make up for the lack of EIA}

In the post-assessment, it is necessary to verify the emissions of the environmental protection facilities of the original project, to conduct a supplementary evaluation of the changes in the process and equipment of the project, and to propose measures to remedy the problems. Compared with conventional EIA, postassessment has played a role in "correcting deviation" of construction projects. Chen Ke and others[17] conducted research on the post-evaluation of large department stores. They learned about consumers' evaluation of the mall environment through interviews and questionnaire surveys, and made rectifications based on the results, reflecting the guiding role of post-evaluation on construction projects. Suo Zhilong[18] believes that doing a good job in the main links of oilfield exploitation, namely the post-evaluation of environmental impacts in exploration, drilling, and oil production, can accumulate experience in adopting environmental protection measures to reduce the ecological damage of mining work and the impact on environmental factors. 


\subsubsection{Summarize the experience of environmental protection work}

The post-EIA documents should also draw conclusions, which can guide the implementation of actual environmental protection measures after the project starts operation. Zhou Jia[19] provided the basis and suggestions for the post-evaluation work of an oil and gas field development. Due to the long history of the oil field, the relevant laws and regulations were not issued at the time of construction, and the early EIA documents could not reflect the true situation, and the "Three Simultaneous" system was not effective and believed that the evaluation should start with the project overview, the regional environmental status, the effectiveness of environmental protection measures, the integrity of the environmental management system, and the accuracy of environmental forecasts.

\subsection{3 romote the improvement of relevant standards}

In some cases, some scholars think about the results of post-evaluation of environmental impacts, and put forward suggestions on environmental protection measures, standards, and methods. Shi Deyu[20] conducted a post-evaluation on the Beijing-Tianjin Intercity Railway Passenger Dedicated Line, and based on this, put forward a proposal to improve the existing acoustic environment standard and specification system. If the proposal is adopted, it will have an impact on the existing environmental protection technology. Yang Yangang[21] and others systematically analyzed the post-evaluation of environmental impact of highway construction projects involving ecologically sensitive areas, and put forward suggestions for the problems in post-evaluation, that is, to clarify the powers and responsibilities of highway management in ecologically sensitive areas, strengthen related normative systems and management systems, strengthen the construction and maintenance of environmental protection measures in ecologically sensitive areas, increase environmental protection professionals and financial support, etc.,It provides a further reference for the post-evaluation of road environmental impact in important ecologically sensitive areas.

\section{Conclusion}

The environmental and ecological impacts of planning implementation or project construction and operation, the task of EIA is to analyze, predict and evaluate these impacts, and require environmental protection measures for the impact.

The most commonly used method of planning EIA is the "Three Lines and One List" analysis method. The "Three Lines and One List" can exclude construction projects that do not meet the requirements of the planning EIA from the planning scope. At the same time, all the work results of the planning EIA provide the basis for the environmental assessment work of construction projects that are allowed to enter the planning, which is the guidance and guidance of the construction project EIA plan.

The purpose of the EIA of construction projects is to propose reasonable and feasible environmental protection measures, and to urge the construction and operation of the project to comply with the "Three Simultaneous" principles, so that the emission of the "three wastes" of the construction project can be reduced to a reasonable range.

After the construction project is allowed to build, if the actual interest of the construction and operation of the project reaches a certain level with the approved EIA documents, it is necessary to conduct a post-evaluation, which has a guiding role in the operation of the project's environmental protection measures.

\section{References}

1. P. Chen, Environment And Development. J. 29. 4647 (2017)

2. W. Shao, Energy And Environment. J. 02. 64-65 (2020)

3. Y. Wang, Y. Dong, D Li, EIA. J. 42. 42-46 (2020)

4. H. Li, T. Chen, X. Zhang, et al, Electric Power Technology and Environmental Protection, J. 35. 15 (2019)

5. Y. Zhang, N. Xu, Y. Long, et al, Environment and Development, J. 29. 24-28 (2017)

6. W. Rong, Z. Han, Energy Conservation. J. 39. 159160 (2020)

7. R. Liang, J. Li, W. Lv, EIA, J. 39. 5-8 (2017)

8. W. Huang, Y. Chen, W. Zhou, China Resources Comprehensive Utilization. J. 38. 131-133 (2020)

9. F. Fan, Environment and Development, J. 32. 11-12 (2020)

10. Z. Shi, J. Wang, Z. Tan, Highway Engineering, OL. http://kns.cnki.net/kcms/detail/43.1481.U.20201021. 1743.004.html

11. C. $\mathrm{Xu}, \mathrm{W} . \mathrm{Xu}, \mathrm{W}$. Zhang, Environment And Development. J. 32. 23-24 (2020)

12. Y. Chen, Environment And Development. J. 32. 20$21(2020)$

13. B. Liu, Environment and Development, J. 31. 25-26 (2019)

14. W. Wang, C. Bi, Environment And Development. J. 32. 21,23 (2020)

15. S. Liu, Environment and Development, J. 31. 16-17. 31 (2019)

16. C.Wei, Environment and Development, J. 32. 23-24 (2020)

17. K. Chen, C. Zhang, Intelligent City. J. 6. 28-29 (2020)

18. Z. Suo, Petrochemical Industry Technology. J. 26. 265,268 (2020)

19. J. Zhou, Regional Governance, J. 02. 115-117 (2020) 
20. D. Shi, Environmental Protection Science. J. 46. 114-119 (2020)

21. Y. Yang, C. Hu, C. Chen, et al, Environmental Ecology, J. 1. 79-82 (2019) 